\title{
As teorias da tradução dialogam com a criação poética
}

\author{
Alcebiades Martins Areas (UERJ) \\ bideareas@gmail.com \\ Viviane Franco da Silva (UERJ) \\ vivianefrancos@outlook.com
}

\section{Resumo:}

É fato que traduzir não significa passar palavras e expressões de uma língua para outra. A complexidade da empreitada vai muito além. A esse respeito, diversos teóricos, estudiosos da tradução, filósofos, escritores, poetas se debruçaram nas últimas décadas, mais especificamente a partir dos anos de 1960, e empreenderam inúmeras discussões sem chegar a uma definição unânime.Muitos deles, inclusive, de forma ousada e inovadoraespecularam, emuitos ainda os seguem, sobre a grande proximidade entre o fazer poético e $\mathrm{o}$ ato de traduzir.

Palavras-chave:Tradução. Teoria.Traduzibilidade.Criação. Poética.

\begin{abstract}
:
$\mathrm{Si}$ sachetradurre non vuoldirevolgere parole edespressioni da un sistema linguisticoall'altro. La complessitàdeltradurrevamoltooltre. Riguardo a ciòparecchiteorici, studiosidellatraduzione, filosofi, scrittori, poeti si sono occupatinelle ultime decade, piùspecificamente a partir dagli anni '60 del XXsecolo, e hannointrapesoparecchidibattitisenzaarrivare a un' unicadefinizione. Moltidiessi, appunto, in manierarischiosa e innovatrice, hannospeculato, e ancora tanti li inseguono, sulla grande prossimitàtrail fare poetico e l'attodeltradurre.
\end{abstract}

Parole-chiave: Traduzione. Teoria. Traduttibilità. Creazione. Poetica. 


\begin{abstract}
It is a fact that translating does not mean transferring words and expressions from a language to another since the intricacy of the task goes far beyond. Many theorists, translation scholars, philosophers, writers and poets have reflected on it forthe last decades, more specifically from the 1960's on, and have held several discussions without reaching a unanimous definition. A number of them, still followed by many, have been daring and innovative in speculating about the great similarity between poetry writing and the act of translating.
\end{abstract}

Key words: Translation.Theory.Translatability.Creation.Poetics

\title{
Introdução
}

Os estudos da tradução não podem ser considerados abundantes, como o são os estudos sobre a criação poética. Enquanto encontramos em Aristóteles uma teoria completa sobre o fazer poético, o mesmo não podemos fazer com a tradução. No entanto, ainda que relativamente recentes, os estudos da tradução encontram apoio em diversas disciplinas, que, de maneira indireta, dialogam com o processo tradutório. A principal delas, pode-se dizer, é a linguística. Através de aspectos linguísticos, analisou-se questões como a possibilidade da tradução, a similaridade entre as línguas e aspectos culturais da língua. Roman Jakobson demonstra através de muitos exemplos suas concepções da tradução, partindo de um ponto de vista linguístico mais objetivo, mas jamais deixando de observar as particularidades da tradução poética. 
Por outro lado, encontramos em Walter Benjamin uma maneira essencialmente filosófica de pensar a tradução. Na obra $A$ tarefa do tradutor, deparamo-nos com uma profunda teoria do processo tradutório, que assume proporções universais, como é próprio das teorias filosóficas.

Verificamos, ao estudar as teorias da tradução, que, grande parte de seus teóricos são, também, críticos do fazer poético ou, ainda: são eles mesmos, como é o caso de Haroldo de Campos, poetas.

Não é difícil, portanto, perceber que as teorias sobre a criação poética estão intimamente ligadas à tradução.

O objetivo deste trabalho é, portanto, elencar teorias da tradução escolhidas pelo critério da interdisciplinaridade, a fim de demonstrar a grande relevância dos estudos sobre a criação poética nas teorias da tradução.

\section{A tradução como forma de criação poética}

Muitos teóricos da tradução, de diversas disciplinas, foram capazes de identificar elementos que caracterizam a tradução poética como uma forma de criação. É possível verificar esse fato por vertentes tanto linguísticas quanto filosóficas.

Haroldo de Campos $^{1}$ não economiza neologismos para nomear o trabalho do tradutor de obra poética: transcriação, transluciferação, reimaginação, entre outros. Para traduzir, é necessário recriar o que já foi criado. O tradutor

${ }^{1}$ CAMPOS, H. Da transcriação: poética e semiótica da operação tradutora. Belo Horizonte: FALE/UFMG, 2011. p.10. 
é, portanto, também um criador. Walter Benjamin ${ }^{2}$, no entanto, afirma que é necessário distinguir a tarefa do tradutor da tarefa do poeta:

Aqui reside um traço distintivo da tradução por relação à obra poética, porque a intenção desta não visa nunca à língua enquanto tal, a sua totalidade, mas apenas imediatamente determinadas conexões linguísticas de conteúdo. A tradução não se encontra, porém, como a poesia, por assim dizer, no próprio interior da floresta da língua, mas sim fora dela, frente a ela, e sem poder entrar nela, ela invoca o original para aquele lugar único, onde, de cada vez, o eco pode fazer ressoar uma obra de língua estrangeira na sua própria língua. (p.8)

Afirma, ainda, que "não há nenhuma Musa da filosofia como também não há nenhuma Musa da tradução.” (p.8) Para ele, é preciso respeitar o "modo de querer dizer", pois este sim é universal, este sim reconcilia todas as línguas e deixa de lado todas as suas diferenças. Não se deve levar em conta o "que se quer dizer", mas sim o "modo de querer dizer". Para ele, "a inessencialidade é uma característica do mau tradutor"(p.8). Ao tradutor cabe a cunhagem de uma nova língua sagrada, uma língua em que "estão conservados sem tensões e silenciosamente os últimos segredos, com os quais todo o pensamento se ocupa" (p.8).

\section{Impossibilidade da tradução poética}

Tema recorrente nas teorias da tradução, a impossibilidade da tradução poética é vista como regra pela teoria tradicional da tradução. Visto que é impossível verter o sentido original de uma língua para a outra, pois a simples modificação lexical é suficiente para a modificação do sentido, a tradução poética é considerada, por muitos, impossível.

2BENJAMIN, W. A Tarefa do Tradutor. Disponível em: http://www.c-e-m.org/wpcontent/uploads/a-tarefa-do-tradutor.pdf. Acesso em:15/03/2014. p.8. 
Haroldo de Campos reverte tal argumentação em seu Da transcriação: poética e semiótica da operaşão tradutora, remetendo-se mais uma vez à ideia de recriação.

Estabeleci, como limite negativo da reflexão, a postulada impossibilidade da tradução da 'sentença absoluta' (Albrecht Fabri) ou da 'informação estética' (Max Bense), uma vez que, para o primeiro, a possibilidade da tradução decorreria sempre da 'deficiência da sentença' (a tradução operaria sobre o que não é linguagem num texto, ou seja, sobre o resíduo não linguístico do processo de significação; em outros termos, o significado referencial); para o segundo, essa impossibilidade decorreria da 'fragilidade' da 'informação estética', que seria 'inseparável de sua realização singular’. (CAMPOS, 2011, p. 15-16)

A tradução não é mais vista como menor que o original. É uma recriação daquela, é uma produção e não uma reprodução. Com essa argumentação, não é mais possível pensar numa impossibilidade da tradução, já que é derrubada a concepção de fidelidade e literalidade.

Por outro lado, Benjamin afirma que a "traduzibilidade das formas literárias deve ser considerada, mesmo que sejam intraduzíveis para os leitores" (p.1) e que quanto "mais elevada for a forma de uma obra, tanto mais esta mesma se mantém ainda traduzível."(p.1) Para ele, a traduzibilidade pertence à obra. Algumas a possuem, outras não. E, quando a obra é traduzível, não significa que a tradução é essencial a ela, mas que há uma significação no original que é exteriorizada na sua tradução.

Já para Jakobson ${ }^{3}$ "toda experiência cognitiva pode ser traduzida e classificada em qualquer língua existente." (JAKOBSON, 2007, p.67). Oferece-nos uma série de exemplos que comprovariam a persistência cognitiva da significação, após a modificação dos signos. A diferença entre as

${ }^{3}$ R. Aspectos Linguísticos da Tradução. In: . Linguística e Comunicação. São Paulo: Cultrix, 2003. p. 63-72. 
línguas está "essencialmente naquilo que devem expressar e não naquilo que podem expressar.” (JAKOBSON, 2007, p. 69) A linguagem, cognitivamente, depende muito pouco do sistema gramatical. O "nível cognitivo da linguagem não só admite mas exige a interpretação por meio de outros códigos, a recodificação, isto é, a tradução." (JAKOBSON, 2007, p.70)

No entanto, Jakobson não deixa de particularizar a tradução poética:

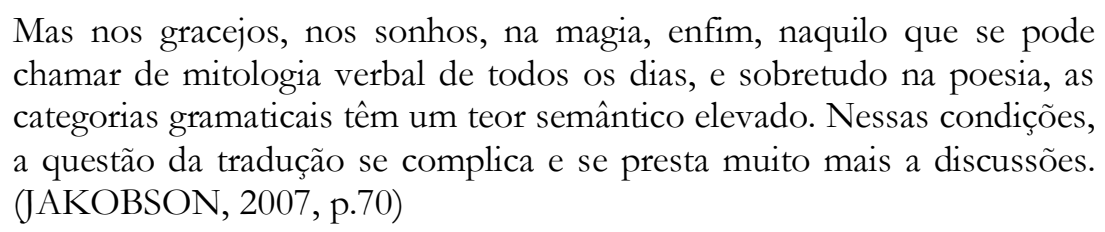

Não fica claro se é impossível a tradução poética na perspectiva de Jakobson, mas é inegável que há uma diferença quanto à importância do aspecto gramatical. A tradução poética trabalha com uma arte da linguagem e, portanto, todos os aspectos desta influenciam na recepção estética.

\section{Críticas às concepções tradicionais de tradução poética}

Ainda a respeito da questão da impossibilidade da tradução, Benjamin não deixa de questionar:como será possível a tradução se, a restituição de sentido já não é essencial e ao tradutor cabe o amadurecimento das "sementes da língua pura"(p.9)? A partir desse questionamento, lança sua crítica sobre os conceitos tradicionais de liberdade e fidelidade na tradução. Para o ensaísta, tais conceitos mostram-se ineficazes diante de uma teoria que procure na tradução uma coisa diferente da restituição do sentido."Demonstra a falta de eficiência dessas concepções quando elas frequentemente discordam, pois "como pode precisamente a fidelidade levar a cabo propriamente a restituição de sentido"? A restituição de sentido não é garantida jamais pela fidelidade à palavra. Pelo contrário, a fidelidade à forma prejudica a fidelidade ao 
sentido.Novamente, é preciso ser fiel ao "modo de querer dizer" e não à forma nem à "restituição do sentido"(p.9).

Benjamin ainda nos presenteia com sua definição de uma boa tradução:

A verdadeira tradução é transparente, ela não oculta o original, não lhe rouba a luz, faz com que, inversamente, a língua pura, reforçada através do seu próprio 'médium', incida com maior plenitude sobre o original. Isso consegue-o acima de todo a literalidade da sintaxe na tradução e mostra precisamente que o elemento original do tradutor é a palavra e não a frase. Porque a frase é o muro que defende a língua do original, a literalidade, a arcada. (p.10)

Já Haroldo de Campos faz forte crítica a uma visão "naturalizada" de tradução, ligada aos pressupostos ideológicos de restituição da verdade (fidelidade) e literalidade (subserviência da tradução a um presumido "significado transcendental" do original)". Classifica essas ideias como mais “neutras", ou mais "pejorativas". (CAMPOS, 2011, p.10)

As críticas às concepções tradicionais de tradução estão relacionadas, principalmente, à forma objetiva de se pensar um objeto altamente subjetivo. Quando se trata de captura de sentido e, principalmente, de tradução poética, não se pode engessar as regras e exigir uma reprodução da forma e do sentido. A proposta de Benjamin em relação ao "modo de querer dizer" exige do tradutor uma sensibilidade criadora, sensibilidade esta que jamais pode ser submetida a pressupostos objetivamente estabelecidos. Não se pode atribuir o êxito de uma boa tradução ao esforço quase religioso de manutenção da forma, de restituição de sentido, quando o verdadeiro "modo de querer dizer" houve sido perdido. 
Proponho, então, que a capacidade humana de simbolização, evidente nos mitos, lendas e poesia, seja levada em conta ao se pensar a tradução poética.

\section{A questão da língua}

Como matéria prima tanto para o original quanto para a tradução, a questão da língua é investigada exaustivamente nas teorias da tradução. As vertentes mais linguísticas demoram-se nas descrições de exemplos de termos, enquanto as filosóficas atêm-se mais aos fatores mais viscerais das línguas.

Para Benjamin, a tradução é resultado de uma relação íntima entre a língua de partida e a língua de chegada. E, para enaltecer sua importância, afirma que a tradução é um "modo absolutamente original de representação, não podendo ser encontrada no domínio da vida não linguística." (BENJAMIN, p.4).

Sobre o parentesco entre duas línguas, Benjamin afirma que este "é testemunhado muito mais profunda e determinadamente numa tradução do que na semelhança superficial e indefinível de dois poemas." (BENJAMIN, p.4).

Para se compreender a autêntica relação entre original e tradução devemos empregar um critério, cujo propósito é completamente análogo à dos processos reflexivos nos quais a crítica do conhecimento tem de provar a impossibilidade de uma teoria da imagem-cópia. Se aqui se mostra que no conhecimento não pode haver objetividade, nem sequer a exigência de objetividade, se ele consistir numa imagem-cópia do real, ali, por seu lado, é demonstrável que nenhuma tradução será possível se aspirar, como se fosse a sua última essência, à semelhança com o original. Pois na sua persistência vital - nome que seria impróprio se não 
designasse metamorfose e renovação do vivente - o original altera-se. (BENJAMIN, p.4).

Aqui, Benjamin utiliza a "crítica do conhecimento" como exemplo para nos mostrar que a tradução jamais pode pretender-se uma cópia do real. Rompe, então, com a concepção aristotélica de cópia e imitação. E explica: o original modifica-se com o tempo. Além disso, afirma que não pode haver objetividade no conhecimento, criticando, dessa forma, qualquer teoria sobre literalidade da tradução. Para ele, deve-se procurar o essencial dessas metamorfoses na "vida própria da língua e de suas obras", e não na "subjetividade daquele que nasceu depois". (BENJAMIN, p.5)

Segundo Roman Jakobson, (2007, p.64), “o significado de um signo linguístico não é mais que sua tradução por um outro signo que lhe pode ser substituído". E, por essa concepção, definiu "três maneiras de se interpretar um signo verbal". O signo pode ser interpretado por outros signos em sua própria língua, por signos em outra língua e por signos não verbais. A respeito de signos em outra língua, afirma:

Mais frequentemente, entretanto, ao traduzir de uma língua para outra, substituem-se mensagens em uma das línguas, não por unidades de código separadas, mas por mensagens inteiras de outra língua. Tal tradução é uma forma de discurso indireto: o tradutor recodifica e transmite uma mensagem recebida de outra fonte. Assim, a tradução envolve duas mensagens equivalentes em dois códigos diferentes. (JAKOBSON, 2007, p.64).

A tradução, portanto, é nada mais do que a substituição de alguns signos por outros. E essa tarefa é executada pelo tradutor. As duas mensagens são equivalentes, mas não as mesmas. 


\section{Conclusão}

Pudemos verificar nas teorias da tradução de autores como Walter Benjamin, Roman Jakobson e Haroldo de Campos diversas concepções sobre a tradução, que vão além da simples ideia de fidelidade linguística e de transposição de termos de uma língua para a outra. O processo tradutório mostra-se muito mais complexo do que é comumente considerado. Pode-se pensá-lo como um processo de criação, de completude em relação a uma obra original em outra língua, de recriação, de produção e não reprodução. Mas ao mesmo tempo, não é uma imagem-cópia do real, não se encontra dentro da língua, mas fora dela, é a captura do "modo de querer dizer". É, ainda, a substituição de signos por outros, é equivalente, mas não a mesma coisa.

Vimos que, quanto à ideia de intraduzibilidade poética, há bastante controvérsia. Enquanto Haroldo de Campos é categórico ao afirmar que nada é intraduzível, Benjamin atribui essa qualidade a apenas algumas obras, e Jakobson prefere abster-se.

Fatores como a capacidade humana de simbolização, por exemplo, devem ser levados em conta ao se pensar a tradução poética. Todorov encontra em Freud ${ }^{4}$ apoio para uma teoria dos símbolos, que pode ser perfeitamente aplicada a uma teoria da tradução poética.

Um dos conceitos mais importantes é o de "condensação", que consiste em um processo cujo resultado é a "densidade simbólica do dito de espírito", estendendo-se a todos a simbolização linguística. Além do termo condensação, Freud menciona a sobredeterminação e a conversão, expressões pelas quais podem ser designadas "as duas espécies de condensação, na simultaneidade ou na sucessão." (TODOROV, 1979, p.254)

4 TODOROV, T. A retórica de Freud. In: . Teorias do Símbolo. Lisboa: Edições 70, 1979. p. $247-281$ 
Os conceitos aqui mencionados de "condensação", "sobredeterminação" e "conversão" são altamente aplicáveis à tradução poética. Definem processos inconscientes de simbolização, ou seja, de transformação de um sentido em imagem. Há, atualmente, poucos estudos que investigam essa íntima relação da tradução com a simbolização e com os sonhos, por um viés psicanalítico.

As teorias da tradução flertam com uma grande diversidade de disciplinas, e há algumas ainda mal exploradas (como é o caso da psicanálise aplicada à tradução). Não é mais possível manter uma ideia simplista da tradução, presa apenas no campo linguístico. Há muitas perguntas sem respostas. Deve-se estudá-la de maneira ampla, tratando-a com a seriedade que sua complexidade exige.

\section{Referência Bibliográfica:}

BENJAMIN, W. A Tarefa do Tradutor. Disponível em: http://www.c-em.org/wp-content/uploads/a-tarefa-do-tradutor.pdf. Acesso em:15/03/2014.

CAMPOS, H. Da transcriação: poética e semiótica da operação tradutora. Belo Horizonte: FALE/UFMG, 2011. p. 160.

JAKOBSON, R. Aspectos Linguísticos da Tradução. In: Linguistica e

Comunicação. São Paulo: Cultrix, 2003. p. 63-72 .

TODOROV, T. A retórica de Freud. In: . Teorias do Simbolo. Lisboa: Edições 70, 1979. p. 247-281. 